\title{
Effect of Water-Cement Ratio on Flexural Strength of RC Beams Made with Partial Replacement of Coarse Aggregates with Coarse Aggregates from Old Concrete
}

\author{
Mahboob Oad \\ Department of Civil Engineering, Quaid- \\ e-Awam University Engineering, Science \\ \& Technology, Pakistan \\ engrmahboob04@gmail.com
}

\author{
Abdul Hafeez Buller \\ Department of Civil Engineering, Quaid- \\ e-Awam University Engineering, Science \\ \& Technology, Pakistan \\ ah.buller@quest.edu.pk
}

\author{
Bashir Ahmed Memon \\ Department of Civil Engineering, Quaid- \\ e-Awam University Engineering, Science \\ $\&$ Technology, Pakistan \\ masher_m@hotmail.com
}

\author{
Noor Ahmed Memon \\ Department of Civil Engineering, Quaid- \\ e-Awam University Engineering, Science \\ \& Technology, Pakistan \\ nahmedmemon@gmail.com
}

\author{
Zaheer Ahmed Tunio \\ Department of Civil Engineering, Quaid- \\ e-Awam University Engineering, Science \\ \& Technology, Pakistan \\ zaheerahmedtunio@gmail.com
}

\author{
Muneeb Ayoob Memon \\ Department of Civil Engineering, Quaid- \\ e-Awam University Engineering, Science \\ \& Technology, Pakistan \\ engr.muneebmemon@gmail.com
}

\begin{abstract}
This research paper presents an experimental evaluation of the effect of water-cement ratio on the flexural strength of reinforced concrete beams made with $\mathbf{5 0 \%}$ replacement of coarse aggregates with recycled concrete aggregates (RCA). 72 reinforced concrete beams were cast using $0.54,0.6,0.65$ and 0.70 water-cement ratio. In each ratio, 12 beams were cast using RCA and 3 beams were cast using allnatural coarse aggregates (NCA). Beams were cured for 7 and 28 days. After curing, all beams were tested with central point load in a universal load testing machine. From the obtained results, it is observed that the maximum reduction in flexural strength of RCA beams is about $28 \%$ when compared to the 0.54 w/c ratio beams of the same group and $31.75 \%$ in comparison to NCA beams cast with same w/c ratio. The maximum deflection and average strain in beams remained within limits. The observed cracking pattern shows shear failure of all beams.
\end{abstract}

Keywords-recycled concrete aggregates; green concrete; reinforced concrete; beams; flexural strength; water/cement ratio

\section{INTRODUCTION}

Demolishing of old structures generates huge amounts of demolishing waste. Proper management of this waste is essential. For a long time, dumping of this waste in landfills was the main practice. Research on this issue led to the utilization of useable materials in new constructions. A big percentage of this waste is old concrete which can be used as coarse aggregates in new concrete. This technique not only solves, to some extent, the management issue of demolished waste and paves the way to save the natural coarse aggregates but also can lead to financial benefit of the new construction. To this end, different researchers remained engaged in exploring the possibilities of utilization of this waste by conducting research to understand the behavior of this material [1-6]. Authors in [8] conducted research on reinforced concrete beams made by $50 \%$ replacement of natural coarse aggregates with aggregates from old concrete to study its flexural behavior. The results show good flexural behavior correlation with the one from reinforced concrete beams of the same size and steel reinforcement made with $100 \%$ natural coarse aggregates (normal concrete). Authors in [17-18] presented flexural stress-strain behavior of reinforced concrete beams made with recycled concrete aggregates for normal and rich mix concretes. They used 7 - and 28-day curing. They recorded $8.8 \%$ and $2.59 \%$ reduction in flexural strength of the proposed beams for normal and rich mix beams respectively.

Water-cement $(\mathrm{w} / \mathrm{c})$ ratio plays a vital role in concrete mix to ensure the workability which in turn ensures the proper strength of reinforced concrete. It is a general observation that on old concrete as coarse aggregates water absorption is higher than that of normal coarse aggregates [7]. This demand of higher w/c ratio in concrete mix using old concrete as coarse aggregates to make the new concrete workable to the extent 
that it does not give rise to bleeding or honeycombing. In a research to study the effect of different $\mathrm{w} / \mathrm{c}$ ratios on sulphate resisting concrete, authors in [9] used four different ratios ranging from 0.45 to 0.75 . They concluded that lean mixes and compression members were affected more than rich mixes and flexural members respectively. They also observed that concrete mix with w/c ratio more than 0.55 was affected more when exposed to sulphate attack. On the study of the effect of w/c ratio on Portland cement, author in [10] studied the effect of different w/c ratios with Negerian Grande 42.5 OPC. He used w/c ratio ranging from 0.5 to 0.6 with increment of 0.05 to produce normal concrete in 9 batches. He also used 2 different sizes of $19 \mathrm{~mm}$ and $12.5 \mathrm{~mm}$ washed gravel. He concluded that only concrete mix with $19 \mathrm{~mm}$ washed gravel and $0.5 \mathrm{w} / \mathrm{c}$ ratio obtained marginally higher flexural strength than the standard value. He also observed that although the flexural strength of the above-mentioned mix remained within the range of standard values yet, the tensile strength of the same mix remained less than standard values. Towards the research on lateritic concrete and the effects of w/c ratio on it, authors in [11] conducted experimental work to study the effects of w/c ratio on the workability and compressive strength of concrete and lateritic concrete. They used w/c ratio in the range of $0.55-$ 0.8 and curing periods of 7 and 28 days. They observed decrease in compressive strength of concrete when w/c ratio was more than 0.65. Based on the experimental results of slump and compressive strength, they concluded that lateritic concrete is not as suitable and workable as normal concrete. In [12], authors conducted experimental work to evaluate the modulus of rupture of concrete with different w/c ratios. They used 15 prototype beams with different w/c ratios. After curing of 28 days, the test results showed that optimum flexural strength was obtained with w/c ratio of 0.58 beyond which they observed significant reduction in flexural strength. Therefore, they concluded that 0.58 is the optimum w/c ratio to obtain maximum flexural strength of concrete prototype beams.

Authors in [13] conducted experimental study using M20 concrete to check the effect of water type i.e. tap water, waste water, well water, bore well water and mineral water on the compressive strength of concrete. They cast $150 \mathrm{~mm}$ cubes and cured them for 7 and 28 days. After curing, they tested the cubes. Based on the obtained results, they concluded that there was no significant variation in concrete compressive strength. Although it is surprising that they used waste water, the results show no countable variation in the compressive strength results. Authors in [14] researched the effect of water ratio on Portland cement pastes. They used w/c ratio in the range of 0.19 to 0.5 to prepare cement pastes and studied their composition and morphology. They concluded that lower w/c ratio gave rise to crack propagation and lowered compressive strength.

Finding alternatives of cementitious products is an active research area. Authors in [15] studied the effect of w/c ratio on the mechanical properties of blended cement containing bottom ash and limestone. They used $10 \%$ of both limestone and bottom ash with $0.35-0.55 \mathrm{w} / \mathrm{c}$ ratio to study the compressive and flexural strength of cement mortar specimens cured for 2 , 7, 28 and 60 days. Test results showed that both compressive and flexural strength were same to the ones of control concrete specimens at w/c ratio of 0.4 but they reduced with increase in w/c ratio untill it reached 0.5 . They attributed this phenomenon to the pozzolanic reaction of the cement. Based on the test results they concluded that at 28 days curing, both flexural and compressive strength of the proposed product went higher than the control specimens. They also concluded that as w/c ratio increased beyond 0.4 to 0.5 both blended cement and ordinary cement gave higher values of compressive and flexural strength. This shows the validity of the use of the proposed product in concrete mix. Authors in [16] conducted research to study the effect of $\mathrm{w} / \mathrm{c}$ ratio and cement content on the properties of fresh concrete without admixtures using 8 different mortar mixes. Based on the test results they developed relationships for fresh concrete without admixtures.

The experimental and analytical research remains active on the subject matter, but the scatter of results and, in a few cases, the unavailability of data, proves that more research is required to build confidence for the use of concrete made with partial replacement of coarse aggregates with old concrete. This motivated the current research. This paper presents the effect of w/c ratio on the flexural strength of reinforced concrete beams made with $50 \%$ replacement of natural coarse aggregates with coarse aggregates from demolished concrete. Selection of $50 \%$ replacement is based on the outcome of the authors' research presented in [7]. To achieve the proposed task, four different water cement ratios i.e. $0.54,0.6,0.65$ and 0.7 were used to study the effect of w/c ratio on the flexural strength of $\mathrm{RC}$ beams made with partial replacement of natural coarse aggregates with recyclable aggregates. In each value of w/c ratio, 18 reinforced concrete beams were prepared. These beams were prepared in two groups. In the first group, 12 beams were cast using $50 \%$ replacement of natural coarse aggregates with recycled aggregates from old concrete and 6 beams with all-natural coarse aggregates. Concrete ingredients for all w/c ratios were batched using 1:2:4 mix with weight batching process. In all beams ordinary Portland cement, hill sand, $50 \%$ natural crushed coarse aggregates of size up to $25 \mathrm{mmand}$ and $50 \%$ recycled aggregates from old concrete of size up to $25 \mathrm{~mm}$ as coarse aggregates were used. $50 \%$ of these beams were cured for 7 days and $50 \%$ were cured for 28 days. Water curing in standard manner was used. Old concrete in the shape of large blocks was collected from demolished, approximately 60 -year-old reinforced concrete buildings. The large blocks of old concrete were hammered down to the required size. Screening of the small particles was done to separate and discard the cracked particles. Sieving was done to obtain aggregates of size up to $25 \mathrm{~mm}$ in standard manner. To reinforce the beams $2 \# 4$ deformed bars were used both in tension and compression zones with \#3 stirrups at $150 \mathrm{~mm}$ center to center distance. The dimension of all used beams was $150 \mathrm{~mm} \times 150 \mathrm{~mm} \times 900 \mathrm{~mm}$. After curing, all beams were tested in a universal testing machine with central point load as per ASTM C-293. The obtained results are presented, analyzed and compared with the ones from the control specimens. Analysis of the results shows that old concrete as coarse aggregates can be used in new concrete without much loss of flexural strength. The outcome of this research work is a landmark in understanding the effect of different $\mathrm{w} / \mathrm{c}$ ratios on the flexural strength of reinforced concrete beams. This research work used four water cement ratios with commonly used concrete mix ratio. However, more w/c ratios and concrete mix ratios with 
old concrete from different sources may be used to refine the results.

\section{MODEL DESCRIPTION AND TESTING}

This work aims to evaluate the effects of w/c ratio on the flexural strength of reinforced concrete beams made by $50 \%$ replacement of natural coarse aggregates with old concrete. To achieve this purpose, a total of 72 reinforced concrete beams were prepared. The old concrete was collected from Nawabshah city. The old concrete, collected in shape of large blocks, comes from a school building about 60 years old. The large concrete blocks were hammered down to size approximately equal to $25 \mathrm{~mm}$. Due to the age and hammering action on large blocks, smaller pieces might have been cracked. The cracked particles should be week and may produce weaker concrete specimens. Therefore, the material was screened to separate and discard the cracked particles. Sieving was then performed in standard way to get aggregates of size up to $25 \mathrm{~mm}$. Sieving of natural coarse aggregates was also performed in a similar fashion. The comparison of the gradation of both coarse aggregates is shown in Figure 1. The size of all beams is kept the same and equal to $150 \mathrm{~mm} \times 150 \mathrm{~mm} \times 900 \mathrm{~mm}$ (Figure 2). Ordinary Portland cement, hill sand, crushed natural coarse aggregates and old concrete as coarse aggregates in $50 \%$ proportion were then batched using batching weight method. Four different w/c ratios i.e. $0.54,0.6,0.65$ and 0.7 were used to prepare the reinforced concrete beams. Under normal conditions the commonly used concrete mix is 1:2:4 therefore it is selected in this research work. To reinforce the beams, deformed bars were used. 2\#4 bars were used in both tension and compression zones respectively. To provide shear reinforcement in beams, \#3 bars at $150 \mathrm{~mm}$ center to center were used. For each value of w/c ratio mentioned above, 12 beams were cast using $50 \%$ replacement of natural coarse aggregates with old concrete. $50 \%$ of these beams were cured for 7 and $50 \%$ for 28 days respectively. Water curing in standard manner was adopted.

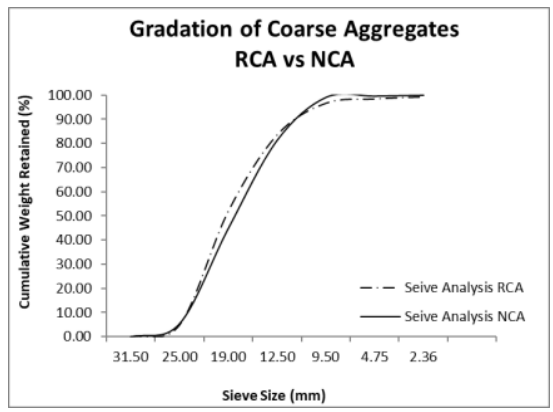

Fig. 1. Gradation of coarse aggregates

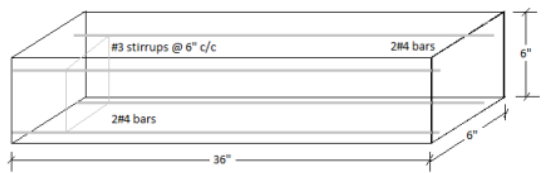

Fig. 2. Beam dimensions and reinforcement

To compare the results of the proposed beams, 24 reinforced beams with $100 \%$ natural coarse aggregates were also prepared with the same size and reinforcements. Similar to the procedure adopted for the proposed beams, these beams were cast and cured, but in each group the number of beams was restricted to 3 . Table I gives details for all the beams. After the elapse of curing time, all the beams were tested in a universal load testing machine with central point load in accordance with ASTM C-293. Figure 3 shows the loading arrangement of a typical beam. During the testing, load, deflection and strain were observed at regular intervals. Also, cracking in beams was observed and recorded. Flexural strength was then computed numerically from the recorded load. The average values of the above-mentioned parameters are given in Tables II and III for 7- and 28-day cured beams.

TABLE I. DETAILS OF THE REINFORCED CONCRETE BEAMS

\begin{tabular}{|c|c|c|c|c|c|c|}
\hline \multirow{2}{*}{ Group } & \multirow{2}{*}{$\begin{array}{c}\text { w/c } \\
\text { ratio }\end{array}$} & \multirow{2}{*}{\begin{tabular}{c} 
RCA \\
\cline { 3 - 7 }
\end{tabular}} & $\begin{array}{c}\text { Number of beams } \\
\text { curing }\end{array}$ & $\begin{array}{c}\text { 28-day } \\
\text { curing }\end{array}$ & $\begin{array}{c}\text { Top \& } \\
\text { bottom zone }\end{array}$ & Stirrups \\
\hline \multirow{2}{*}{ G54 } & \multirow{2}{*}{0.54} & 50 & 6 & 6 & $2 \# 4$ & $\# 3 @ 150 \mathrm{~mm} \mathrm{c/c}$ \\
\cline { 3 - 7 } & & 0 & 3 & 3 & $2 \# 4$ & $\# 3 @ 150 \mathrm{~mm} \mathrm{c/c}$ \\
\hline \multirow{2}{*}{ G60 } & \multirow{2}{*}{0.60} & 50 & 6 & 6 & $2 \# 4$ & $\# 3 @ 150 \mathrm{~mm} \mathrm{c/c}$ \\
\cline { 3 - 7 } & & 0 & 3 & 3 & $2 \# 4$ & $\# 3 @ 150 \mathrm{~mm} \mathrm{c/c}$ \\
\hline \multirow{2}{*}{ G65 } & \multirow{2}{*}{0.65} & 50 & 6 & 6 & $2 \# 4$ & $\# 3 @ 150 \mathrm{~mm} \mathrm{c/c}$ \\
\cline { 3 - 7 } & & 0 & 3 & 3 & $2 \# 4$ & $\# 3 @ 150 \mathrm{~mm} \mathrm{c/c}$ \\
\hline \multirow{2}{*}{ G70 } & \multirow{2}{*}{0.70} & 50 & 6 & 6 & $2 \# 4$ & $\# 3 @ 150 \mathrm{~mm} \mathrm{c/c}$ \\
\cline { 3 - 7 } & & 0 & 3 & 3 & $2 \# 4$ & $\# 3 @ 150 \mathrm{~mm} \mathrm{c/c}$ \\
\hline
\end{tabular}

TABLE II. 7-DAY CURED BEAMS

\begin{tabular}{|c|c|c|c|c|c|c|}
\hline \multirow{2}{*}{$\begin{array}{c}\text { w/c } \\
\text { ratio }\end{array}$} & \multicolumn{3}{|c|}{ 50\% RCA } & \multicolumn{3}{c|}{ 0\% RCA } \\
\cline { 2 - 7 } & $\begin{array}{c}\text { Flexural } \\
\text { Strength }\end{array}$ & Strain & Deflection & $\begin{array}{c}\text { Flexural } \\
\text { Strength }\end{array}$ & Strain & Deflection \\
\hline 0.54 & 24.342 & 0.00270 & 4.405 & 25.873 & 0.00279 & 3.957 \\
\hline 0.60 & 22.254 & 0.00275 & 3.909 & 24.141 & 0.00246 & 3.709 \\
\hline 0.65 & 20.118 & 0.00225 & 5.233 & 22.441 & 0.00218 & 4.633 \\
\hline 0.70 & 18.783 & 0.00225 & 5.818 & 21.147 & 0.00215 & 5.250 \\
\hline
\end{tabular}

TABLE III. 28-DAY CURED BEAMS

\begin{tabular}{|c|c|c|c|c|c|c|}
\hline \multirow{2}{*}{ w/c ratio } & \multicolumn{3}{|c|}{ 50\% RCA } & \multicolumn{3}{c|}{ 0\% RCA } \\
\cline { 2 - 7 } & $\begin{array}{c}\text { Flexural } \\
\text { Strength }\end{array}$ & Strain & Deflection & $\begin{array}{c}\text { Flexural } \\
\text { Strength }\end{array}$ & Strain & Deflection \\
\hline 0.54 & 28.15 & 0.00230 & 4.37 & 29.70 & 0.00218 & 3.73 \\
\hline 0.60 & 26.25 & 0.00227 & 4.22 & 28.07 & 0.00245 & 3.86 \\
\hline 0.65 & 23.44 & 0.00233 & 4.76 & 25.05 & 0.00215 & 4.26 \\
\hline 0.70 & 20.27 & 0.00231 & 4.91 & 21.84 & 0.00215 & 4.39 \\
\hline
\end{tabular}
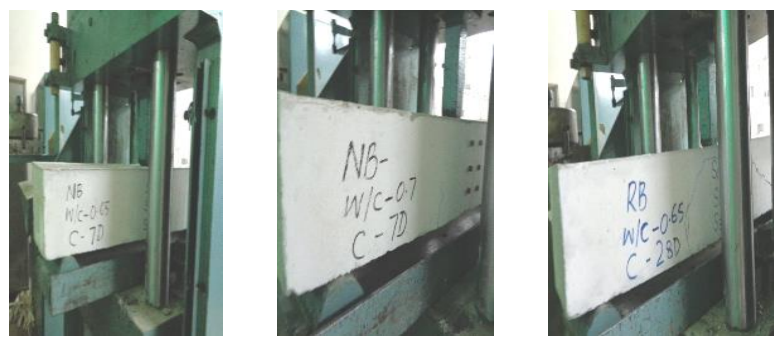

Fig. 3. Loading arrangement

\section{RESULTS AND DISCUSSION}

The results of load testing were analyzed for maximum values of proposed parameters. It was observed that for the same w/c ratio the difference remained within $15 \%$. Numerically computed flexural strength vs strain is plotted in Figures 4 to 7 for 7 - and 28-day cured beams of $0.54,0.60$, 0.65 and $0.70 \mathrm{w} / \mathrm{c}$ ratios respectively. 
(a)

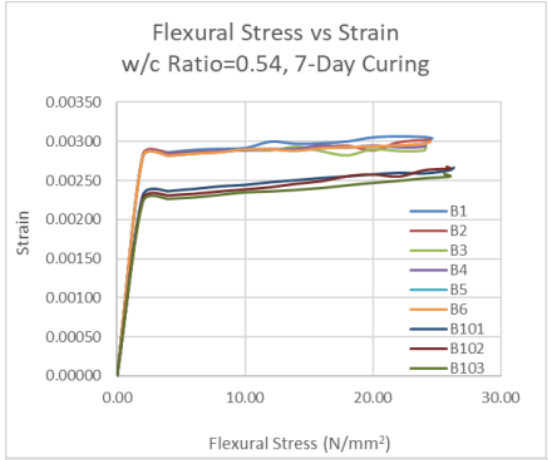

(b)

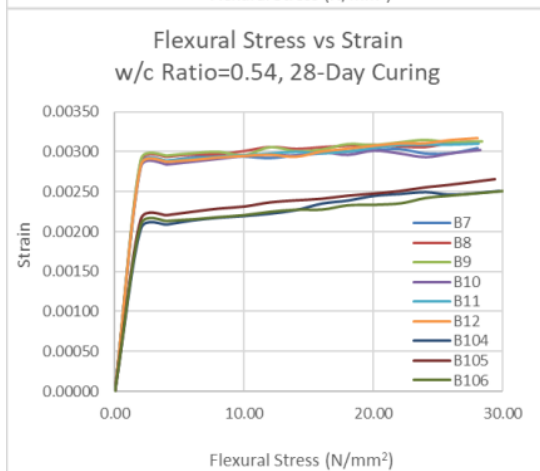

Fig. 4. Flexural strength vs strain for $w / c$ ratio $=0.54$. (a) 7-day curing, (b) 28-day curing.

(a)

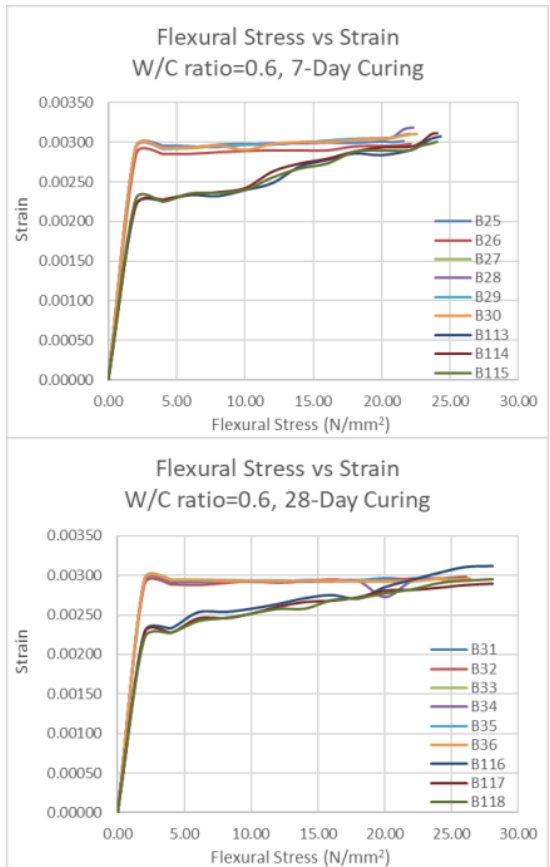

Fig. 5. Flexural strength vs strain for $w / c$ ratio=0.60. (a) 7-day curing, (b) 28-day curing.

It is observed that the pattern of the graphs remained similar within the w/c ratio. Peak values of RCA beams exhibited lower maximum flexural strength and higher strain than NCA beams. It was also observed that with increase in w/c ratio (i.e. 0.65 and 0.70 ), strain fluctuated at higher values of flexural strength, but the peak values of strain for all beams remained within limits. The similar trend of flexural strength and strain is observed in both RCA and NCA beams. Maximum values of deflection (Tables II and III) remained within the limits of approximate maximum deflection except for 3 values of 7-day cured beams. Out of these, 7 -day cured beams of $0.65 \mathrm{w} / \mathrm{c}$ ratio exhibited $4.66 \%$ higher deflection, and both RCA and NCA beams of $0.7 \mathrm{w} / \mathrm{c}$ ratio exhibited $5 \%$ and $16.36 \%$ higher values. This may be due to their higher w/c ratio and early age of concrete because deflection of 28-day cured beams of same w/c ratio remained within limits.

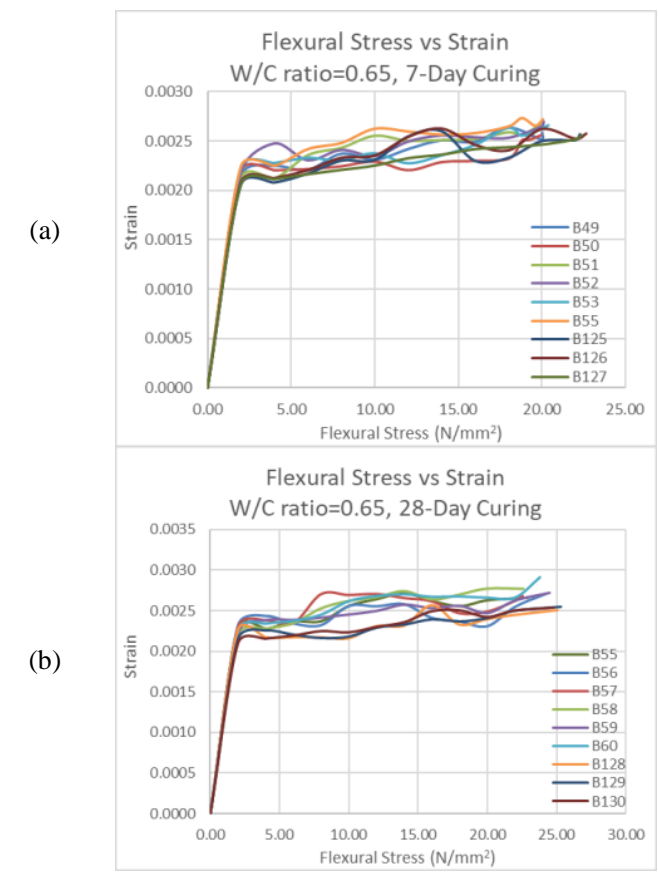

Fig. 6. Flexural strength vs strain for $w / c$ ratio $=0.65$. (a) 7-day curing, (b) 28-day curing.

Flexural strength vs w/c ratio is plotted in Figure 8 for 7 and 28 days of curing. From Figure 8 , it is observed that the residual flexural strength of 7-day cured RCA beams in comparison to the RCA beams of $0.54 \mathrm{w} / \mathrm{c}$ ratio is $91.42 \%$. $82.34 \%$ and $68.47 \%$ for beams made with $0.60,0.65$ and 0.70 w/c ratio respectively. Similar trend of reduction of flexural strength with increase in w/c ratio is observed for 7-day cured NCA beams with minimum of $6.7 \%$ and maximum of $18.27 \%$ loss in flexural strength. While comparing 7-day cured RCA beams with 7-day cured NCA beams keeping w/c ratio of 0.54 of NCA beams as base measure, it is observed that the reduction of flexural strength is $94.43 \%, 86.01 \%, 77.75 \%$ and $72.59 \%$ for w/c ratios of $0.54,0.60,0.65$ and 0.70 respectively. Similar to 7-day cured beams, 28-day cured RCA beams exhibited $93.25 \%, 83.27 \%$ and $72.01 \%$ residual flexural strength for RCA beams of w/c ratio equal to $0.60,0.65$ and 0.70 respectively. Same cadre NCA beams also exhibited reduction in flexural strength of $5.49 \%$ minimum and $28.79 \%$ maximum. Keeping NCA beams with w/c ratio equal to 0.54 as base measure, residual flexural strength of RCA beams is recorded as $94.78 \%, 88.38 \%, 78.92 \%$ and $68.25 \%$ for $\mathrm{w} / \mathrm{c}$ ratios equal to $0.54,0.60,0.65$ and 0.70 respectively. 
(a)

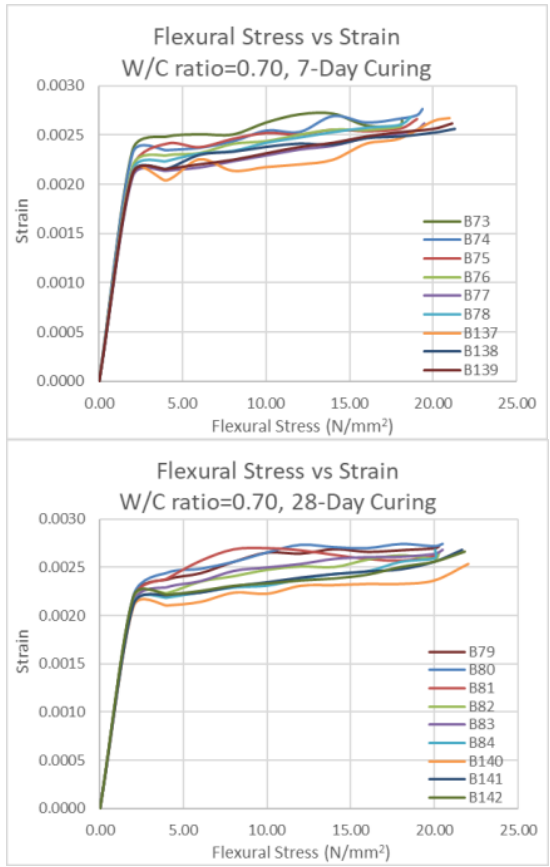

Fig. 7. Flexural strength vs strain for $w / c$ ratio=0.70. (a) 7-day curing, (b) 28-Day curing

(a)

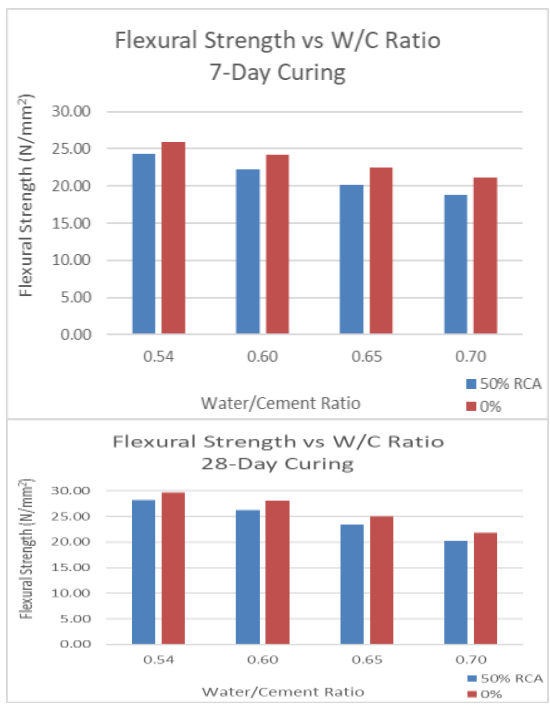

Fig. 8. Flexural strength vs w/c ratio: (a) 7-day curing, (b) 28-Day curing

First crack, cracking pattern and cracks at failure were also recorded (Figure 9). It is clearly observed that the failure mode of the beams is shear failure and is in line with the failure mode of NCA beams. From the above discussion it is evident that increase in w/c ratio leads to reduction in flexural strength of both NCA and RCA beams. However, the maximum reduction in flexural strength of RCA beams with w/c ratio equal to 0.70 is recorded as about $28 \%$ in comparison to RCA beams of 0.54 w/c ratio. The same in comparison to NCA beams of $0.54 \mathrm{w} / \mathrm{c}$ ratio is equal to $31.75 \%$. Therefore, it is concluded that although increase in w/c ratio improves the workability of concrete, it affects flexural strength leading to early failure of the beams. However, it is worth noting that the reduction in flexural strength is independent of the type of coarse aggregate. This infers the viability of the usage of the RCA in concrete.

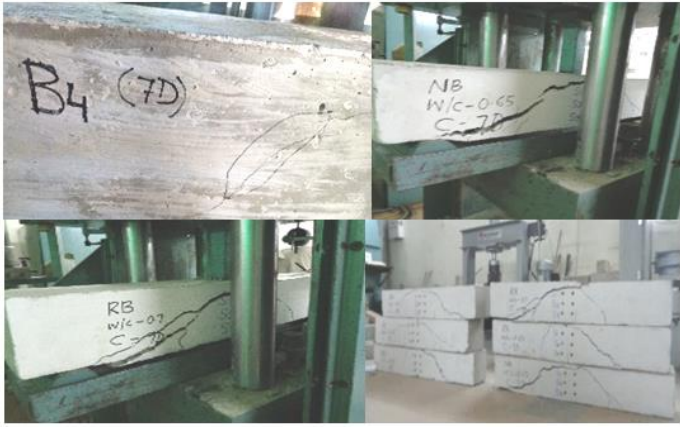

Fig. 9. Cracking in beams

\section{CONCLUSION}

Use of recycled old concrete as coarse aggregates in new concrete and the effects of water-cement ratio on its flexural strength are combined and studied experimentally in this research paper. The dosage of RCA is kept $50 \%$ in all beams. 48 proposed beams were cast using $0.54,0.60,0.65$ and 0.70 w/c ratios. In addition, 24 NCA beams with 6 beams of each w/c ratio were cast to compare the results. Half beams in each w/c ratio were cured for 7 and half for 28 days. All beams were then tested in a universal load testing machine with central point loading. From the obtained results it is observed that RCA can be used in new concrete as deflection, strain, cracking pattern are in good agreement with NCA beams for all considered $\mathrm{w} / \mathrm{c}$ ratios. The results also revealed that flexural strength of the proposed beams reduced with increase in w/c ratio. The maximum strength reduction of proposed beams in comparison to NCA beams made with $0.54 \mathrm{w} / \mathrm{c}$ ratio is equal to $31.75 \%$. Whereas, $26.46 \%$ reduction in flexural strength of NCA beams with $0.7 \mathrm{w} / \mathrm{c}$ ratio in comparison to the same group of beams of $0.54 \mathrm{w} / \mathrm{c}$ ratio was noted. Therefore, the strength reduction for the highest $\mathrm{w} / \mathrm{c}$ ratio considered in this research work is within $5 \%$.

\section{REFERENCES}

[1] C. Thomas. J. Setien, J. A. Polanco, "Structural recycled aggregate concrete made with precast wastes", Construction and Building Materials, Vol. 114, pp. 536-546, 2016

[2] S. Omary, E. Ghorbel, G. Wardeh, "Relationships between recycled concrete aggregates characteristics and recycled aggregates concretes properties", Construction and Building Materials, Vol. 108, pp. 163-174, 2016

[3] P. Kathirvel, S. R. M. Kaliyaperumal, "Influence of recycled concrete aggregates on the flexural properties of reinforced alkali activated slag concrete", Construction and Building Materials, Vol. 102, pp. 51-58, 2016

[4] B. A. Memon, "Recent Development on Use of Demolished Concrete as Coarse Aggregates", International Journal of Emerging Technology and Innovative Engineering, Vol. 2, No. 1, pp. 1-11, 2016

[5] S. Tanwani, B. A. Memon, "Tensile Strength of Concrete Cylinders Made by Partial Replacement of Natural Coarse Aggregates with Coarse Aggregates from Old Concrete", International Journal of Emerging Technology and Innovative Engineering, Vol. 1, No. 4, pp. 1-10, 2015

[6] A. A. Bhatti, B. A. Memon, "Strength, Deflection and Cracking Behavior of Concrete Slab Using Demolished Concrete as Coarse Aggregates", International Journal of Engineering Sciences \& Research Technology, Vol. 3, No. 6, pp. 492-506, 2014

[7] M. Oad, B. A. Memon, "Compressive Strength of Concrete Cylinders using Coarse Aggregates from Old Concrete", 1st National Conference 
on Civil Engineering (NCCE 2013-14)-(Modern Trends and Advancements), Muscat, Oman, April 28-29, 2014

[8] B. A. Memon, G. S. Bhatti, "Flexural Behavior of Beam made by Partial Replacement of Natural Aggregates with Coarse Aggregates from Old Concrete", International Journal of Engineering Sciences \& Research Technology, Vol. 3, No. 5, pp. 52-61, 2014

[9] A. Saeed, S. Faisal, "Effect of Different Mix Ratios and Water Cement Ratios on Sulphate Attack on Concrete", 30th Conference on OUR WORLD in Concrete Structures, Singapore, August 23-24, 2005

[10] A. Isaac, "Effects of Using 0.5, 0.55 and 0.6 Water Cement Ratio Separately with Nigerian Grade 42.5R Portland Cement", International Journal of Science, Technology and Society, Vol. 4, No. 6, pp. 80-88, 2016

[11] O. Alawode, O. I. Idowu, "Effects of Water Cement Ratios on the Compressive Strength and Workability of Concrete and Lateritic Concrete Mixes", The Pacific Journal of Science and Technology, Vol. 12, No. 2, pp. 99-105, 2011

[12] D. O. Onwuka, C. T. Awodiji, S. U. Onwuka, "Investigation of the Effect of Water Cement Ratio on the Modulus of Rupture of Concrete", International Journal of Engineering and Computer Science, Vol. 4, No. 7, 2015

[13] R. A. More, S. K. Dubey, "Effect of Different Types of Water on Compressive Strength of Concrete", International Journal on Emerging Technologies, Vol. 5, No. 2, pp. 40-50, 2014

[14] T. Slamecka, F. Skvara, "The Effect of Water Ratio on Microstructure and Composition of the Hydration Products of Portland Cement Pastes", Ceramics, Vol. 46, No. 4, pp. 152-158, 2002

[15] O. O. Olubajo, A. O. Osha, U. A. El Nafaty, H. A. Adamu, "Effect of Water Cement Ratio on the Mechanical Properties of Blended Cement Containing Ash and Limestone", Civil and Environmental Research, Vol. 6, No. 12, pp. 1-10, 2014

[16] K. Marar, O. Eren, "Effect of Cement Content and Water Cement Ratio on Fresh Concrete Properties without Admixtures", International Journal of Physical Sciences, Vol. 6, No. 4, pp. 5752-5765, 2011

[17] M. Oad, A. H. Buller, B. A. Memon, N. A. Memon, "Flexural StressStrain Behavior of RC Beams Made with Partial Replacement of Coarse Aggregates with Coarse Aggregates from Old Concrete Part-1,Ratio 1:2:4", Engineering, Technology \& Applied Science Research, Vol. 8, No. 3, pp. 3048-3053, 2018

[18] M. Oad, A. H. Buller, B. A. Memon, N. A. Memon, S. Sohu, "Flexural Stress-Strain Behavior of RC Beams Made with Partial Replacement of Coarse Aggregates with Coarse Aggregates from Old Concrete Part-2: 1:2:4 Ratio", Engineering, Technology \& Applied Science Research, Vol. 8, No. 5, pp. 3338-3343, 2018 